\title{
A novel method of analyzing daily milk production and electrical conductivity to predict disease onset
}

\author{
J. M. Lukas, ${ }^{*}$ J. K. Reneau, ${ }^{* 1}$ R. Wallace $\nmid \dagger$ D. Hawkins, $\ddagger$ and C. Munoz-Zanzi§ \\ *Department of Animal Science, University of Minnesota, St. Paul 55108 \\ †College of Veterinary Medicine, University of Illinois, Urbana 61802 \\ $\ddagger$ School of Statistics, and \\ §School of Public Health, University of Minnesota, St. Paul 55108
}

\begin{abstract}
This study evaluates the changes in milk production (yield; MY) and milk electrical conductivity (MEC) before and after disease diagnosis and proposes a cow health monitoring scheme based on observing individual daily MY and MEC. All reproductive and health events were recorded on occurrence, and MY and MEC were collected at each milking from January 2004 through November 2006 for 587 cows. The first 24 mo (January 2004 until December 2005) were used to investigate the effects of disease on MY and MEC, model MY and MEC of healthy animals, and develop a health monitoring scheme to detect disease based on changes in a cow's MY or MEC. The remaining 11 mo of data (January to November 2006) were used to compare the performance of the health monitoring schemes developed in this study to the disease detection system currently used on the farm. Mixed model was used to examine the effect of diseases on MY and MEC. Days in milk (DIM), DIM $\times$ DIM, and ambient temperature were entered as quantitative variables and number of calves, parity, calving difficulty, day relative to breeding, day of somatotropin treatment, and 25 health event categories were entered as categorical variables. Significant changes in MY and MEC were observed as early as 10 and $9 \mathrm{~d}$ before diagnosis. Greatest cumulative effect on MY over the 59-d evaluation period was estimated for miscellaneous digestive disorders (mainly diarrhea) and udder scald, at -304.42 and $-304.17 \mathrm{~kg}$, respectively. The greatest average daily effect was estimated for milk fever with a 10.36-kg decrease in MY and 8.3\% increase in MEC. Milk yield and MEC was modeled by an autoregressive model using a subset of healthy cow records. Six different self-starting cumulative sum and Shewhart charting schemes were designed using 3 different specificities (98, 99, and 99.5\%) and based on MY alone or MY
\end{abstract}

Received January 22, 2009.

Accepted August 27, 2009.

${ }^{1}$ Corresponding author: renea001@umn.edu and MEC. Monitoring schemes developed in this study issue alerts earlier relative to the day of diagnosis of udder, reproductive, or metabolic problems, are more sensitive, and give fewer false-positive alerts than the disease detection system currently used on the farm.

Key words: electrical conductivity, health monitoring, milk yield, statistical process control

\section{INTRODUCTION}

Over $33 \%$ of all culling that occurs on the dairy farm happens within the first 100 DIM (Godden et al., 2003). More than half of the culling decisions are related to disease diagnosis (Beaudeau et al., 1993). Occurrence of periparturient cow disorders negatively affects production (Deluyker et al., 1991; Bareille et al., 2003) and reproductive performance (Loeffler et al., 1999; Walsh et al., 2007) resulting in further culling at time of occurrence as well as throughout the whole lactation (Rajala-Schultz and Grohn, 1999; Grohn et al., 2003). Periparturient cow disorders are identified risk factors for displaced abomasa (Rohrbach et al., 1999), mastitis (Oltenacu and Ekesbo, 1994), reproductive tract infections (Stevenson and Call, 1988), anovulation (Walsh et al., 2007), and other diseases (Correa et al., 1993). Early disease detection could reduce the cost of treatment, minimize the magnitude of the negative effect disease has on all aspects of cow performance, and significantly decrease the culling rate throughout lactation.

Milking systems that provide data on milk production (yield; MY) and milk electrical conductivity (MEC) of individual animals at every milking are a steady source of information on each animal. Both measurements, MY and MEC, are sensitive to changes in animal health status. Changes in electrical conductivity of milk are most commonly associated with mastitis (Nielen et al., 1995; de Mol et al., 2001; Norberg et al., 2004). de Mol (2000) suggested, however, that increased electrical conductivity might be associated with problems other than mastitis. A study by Bareille et al. (2003) demonstrated the effect of diseases on MY that started 
as early as $5 \mathrm{~d}$ before diagnosis of a disease and lasted for more than $140 \mathrm{~d}$ postdiagnosis.

Several researchers (Nielen et al., 1995; de Mol, 2000; Edwards and Tozer, 2004) have attempted to develop a scheme that would allow for early disease diagnosis based on cow and milk monitoring. Edwards and Tozer (2004) demonstrated that change in milk yield can be observed as early as $10 \mathrm{~d}$ before the day of diagnosis. The average magnitude of the negative effect was small, less than $10 \%$ up to $3 \mathrm{~d}$ before the day of diagnosis, and therefore hard to detect. Another identified challenge is the large between-cow variability in MY and MEC of healthy cows (de Mol, 2000). One approach used in on-farm milk monitoring software is to use the cow as her own control by calculating her 10-d rolling average and comparing her performance at subsequent milkings to that average. This approach, although addressing the problem of between-cow differences, fails to detect subtle yet sustained changes in MY or MEC that are often associated with the onset of a health disorder (Woolford et al., 1998; Edwards and Tozer, 2004). As a result, disease diagnosis is made after clinical signs of the health problem have induced a greater change in MY or MEC. Developing a monitoring system capable of detecting the small shifts in MY or MEC often associated with subclinical phases of health problems would benefit the producer. Even a nonspecific alert issued several days before diagnosis draws attention to individual animals or groups of animals in need of attention. At this stage a simple preventative management intervention that will eliminate or reduce a stress factor (such as reducing the stocking rate, increasing bedding frequency, or regrouping the animals) might reduce the negative effect of disease on MY.

Studies in on-farm disease detection have used statistical process control (SPC) cumulative sum charts (CUSUM) to identify emergence of health disorders by monitoring water intake in swine (Madsen and Kristensen, 2005) or feed bunk behavior in beef cattle (Quimby et al., 2001). The basic SPC approach uses historical data to describe process performance. The process performance is expressed by identifying the distribution of its output in terms of process mean and variation estimates. These estimates are then used to set confidence limits for process mean and variation. These limits, referred to as upper and lower control limits (UCL, LCL) in SPC terminology, are used to compare current process mean and variation with relevant past parameters. Shewhart SPC charts were targeted to detect changes $>3$ standard deviations (Hawkins and Olwell, 1998). Analysis of nonrandom patterns on Shewhart control charts led to developing of "run rules" that help detect more subtle shifts in process output distribution. The tendency of run rules, however, to increase the number of false alarms has provoked discussion in quality control research (Montgomery, 2005). Another approach is the use of CUSUM charts (Hawkins and Olwell, 1998) which can be optimized to detect subtle $(\leq 2 \mathrm{SD})$ shifts. For processes in which both small and large shifts are of interest, experts suggest plotting both charts (CUSUM and Shewhart; Montgomery, 2005). As mentioned previously, the traditional SPC approach requires collection of historical data. A self-starting CUSUM (Hawkins and Olwell, 1998) is a chart that can be plotted even when no previous data are available. In this procedure an assumed mean of 0 and variation of 1 is continuously updated as new data become available. Hawkins and Olwell (1998) also present the possibility of plotting a Shewhart chart with the self-starting feature. This approach could be extremely useful for identifying emerging disease at the onset of lactation. Both small, sustained shifts as well as large changes in MY or MEC could be identified even when there are limited historical data available.

When developing a monitoring scheme based on data collected during milking, it is important to consider the specificity (Sp) of such a scheme (Hogeveen and Ouweltjes, 2003). A low Sp might undermine the monitoring system when signals triggered by cows' production performance will be ignored because of a great number of false alarms that occur at each milking. Specificity might be improved by increasing the threshold change in MY or MEC necessary to issue an alarm. However, it can be expected that the sensitivity (Sn) of disease detection will be compromised. Management styles, including risk aversion, differ from farm to farm (Barkema et al., 1999; Valeeva et al., 2007). Specificity and Sn settings for detecting diseases must therefore accommodate those differences so that they can be adopted by farm managers with different attitudes toward risk.

The objective of this study was to develop a cow health monitoring scheme based on following individual daily MY and MEC of lactating cows. Three specific aims were outlined as follows: 1) examine MY and MEC before and after disease diagnosis; 2) model MY and MEC of healthy animals; and 3) develop and evaluate a CUSUM-Shewhart cow health monitoring scheme based on MY or on MY and MEC at 3 Sp levels (98, 99, and $99.5 \%$ ).

\section{MATERIALS AND METHODS}

\section{Study Data Set}

Cow level MY and MEC were collected at each milking from January 2004 until November 2006, for 587 cows and 1,048 partial or full lactations resulting in 395,786 usable records. Cows were milked twice daily 
and housed at the Dairy Cattle Research Unit, University of Illinois (Urbana, IL). Milk yield and MEC were measured using the Metatron P21 milk meter (WestfaliaSurge Inc., Naperville, IL) at every milking. To account for the differences in the time between individual cow milkings, MY was standardized for a 24-h period and expressed as kilograms of milk/24 h for each milking. Milk electrical conductivity was originally measured in millisiemens $(\mathrm{mS})$; however, the on-farm parlor management software (DairyPlan, WestfaliaSurge Inc.) recalculated the values and reported them as reference units. According to the software technical support, 500 reported reference units were equivalent to approximately $6 \mathrm{mS}$. Because the exact algorithm for back calculation of millisiemens was not available, reference units were used in the analyses. The DairyPlan software issued a low milk signal for an individual cow whenever her MY deviated by 2.5 or 1.6 SD from her 10-d moving average at the last 1 or 2 milkings, respectively. A high MEC signal was issued whenever MEC deviated by 2.5 or $1.5 \mathrm{SD}$ from the 10-d moving average at the last 1 or 2 milkings, respectively. Two signals (for MEC, MY, or MEC and MY summed) within a 24-h period resulted in a health alarm and were used to create a low MY/high MEC list. This list was created after each milking and used by the herd manager to aid in identifying animals experiencing health problems. From the day of calving through $14 \mathrm{~d}$ postpartum, all cows were physically evaluated daily for feed intake, attitude, rectal temperature, manure score, and uterine discharge. Cows developing clinical disease were treated according to standard farm treatment protocols. Cows were administered recombinant bovine somatotropin (Posilac, Monsanto, St Louis, MO) every 14 d beginning in wk 9 of lactation until dry off. All cows were subject to estrus synchronization. A combination of timed AI and breeding at observed signs of estrus was implemented on the farm. All reproductive and health events were recorded by date (not by milking) and cow ID in the PC Dart herd management software (Dairy Records Management Systems, Raleigh, NC) using an event coding system with a unique code for each event type. Calving difficulty was also recorded.

The study data set was split into 2 data sets. Data set 1 contained all data for the first 24 mo (January 2004 until the end of December 2005). This data set was used to 1) investigate the effects of disease on MY and MEC, 2) model the MY and MEC of healthy animals, and 3) develop a health monitoring scheme to detect diseases based on changes in a cow's MY or MEC. Data set 2 contained the remaining 11 mo of data (January to November 2006) and constituted a holdback sample used to compare the performance of the health moni- toring schemes developed in this study to the disease detection system currently used on the farm.

Weather information was collected from a weather station located $6 \mathrm{~km}$ from the study location. Based on the collected data, a wind-chill and heat index was calculated and incorporated into the weather factor (WF) that was used later in analysis. For temperatures $<11^{\circ} \mathrm{C}$ and wind speed $>5 \mathrm{mph}$, the $\mathrm{WF}$ reflected wind-chill temperatures. For temperatures $>27^{\circ} \mathrm{C}$, dew point temperatures $>16^{\circ} \mathrm{C}$, and relative humidity $>40 \%$, the $\mathrm{WF}$ reflected the heat index. In the remaining temperature, wind speed, and humidity ranges, WF reflected the temperature.

\section{Effect of Health Events on MY and MEC}

The Mixed procedure of SAS (SAS Institute, Cary, $\mathrm{NC}$ ) was used to model the effect of health events on MY and MEC by 2 separate models. Only the first 300 DIM for each cow were used. The term "health events" used in this study refers to diseases experienced by the animals, administered vaccinations, and other procedures. Biopsies, singeing udder hair, and vaginal flush constituted most of the health events grouped into the category "procedure." In data set 1 , events of the same category had to be separated by a period of $6 \mathrm{~d}$ to be considered separate events. For example, if mild mastitis was diagnosed on Monday and then again on Friday, only the first mild mastitis diagnoses was considered for analysis; however, if the same cow was diagnosed with edema and severe mastitis on the same day, both health events were kept for analysis. Diseases were diagnosed based on commonly recognized case definition. The case definitions of most prevalent diseases in the study herd are listed in Table 1.

Table 2 gives a summary of all class variables in the model. Further description is given below. Each health event and day relative to breeding date was made into a class variable. For the 10-d period preceding the day of the event until $7 \mathrm{~d}$ after, each day represented a different level. From d 8 until d 49 postdiagnosis or breeding, each week represented a different level. With d 0 not being assigned, this process generated a 59-d MY and MEC evaluation period ( $-10 \mathrm{~d}$ to $49 \mathrm{~d}$ ) encompassing a health event. A similar approach was taken by Bareille et al. (2003) in their study evaluating the effect of different diseases on MY and DMI. They demonstrated disease effects persisting as long as $140 \mathrm{~d}$. In their study, however, for most of the health problems, the expected MY level was restored by wk 8 or 9 postdiagnosis. Therefore, a 7 -wk disease persistence evaluation period was chosen for our study. Overall, each health event and breeding date variable had 24 levels (23 levels for 
Table 1. Definition of the most common health disorders diagnosed in the study herd

\begin{tabular}{|c|c|c|}
\hline Health disorder & Case definition & Cases, $\mathrm{n}$ \\
\hline Moderate mastitis & Alert, no fever, eating well, abnormal milk, inflamed udder & 176 \\
\hline Severe mastitis & Depressed, off feed, decreased milk production, fever, abnormal milk and/or inflammation & 40 \\
\hline Metritis & $\begin{array}{l}\text { Abnormal uterine discharge with bad odor and clinical signs of systemic involvement } \\
\text { (off feed, depression, fever) }\end{array}$ & 96 \\
\hline Udder edema & Abnormal swelling of udder, cow may also exhibit discomfort in lying or standing position & 50 \\
\hline Milk fever & $\begin{array}{l}\text { Cold ears, gritting teeth, subnormal body temperature, staggering gait, } \\
\text { off feed, not chewing cud, down cow and unable to rise }\end{array}$ & 35 \\
\hline Off feed & $\begin{array}{l}\text { Not eating, cow may have enlarged, gas-distended left flank, depressed, kicking at belly, } \\
\text { repeatedly rising and lying down, straining but no feces passed }\end{array}$ & 35 \\
\hline Pneumonia & $\begin{array}{l}\text { Excessive coughing, labored breathing and/or purulent nasal discharge with animals } \\
\text { off feed, decreased milk production, fever }\end{array}$ & 49 \\
\hline Lameness & Arched back when standing or walking, reluctant to stand or bear weight on limb(s) & 78 \\
\hline
\end{tabular}

the disease period plus 1 level for all days outside the disease period). Somatotropin treatment became a class variable with 15 levels: 1 for the day of bST treatment, 2 to 14 for following $13 \mathrm{~d}$, and NOTREAT for all days outside the treatment period.

Calving difficulty was made into a class variable. Cows experiencing no or moderate calving difficulty $(<5$ on the 5 -point scale) were assigned a no calving difficulty level (NO) for all DIM. Cows experiencing extremely difficult calving, requiring substantial assistance and possibly surgical intervention ( 5 on the 5 -point scale) were assigned a difficult calving level (DIFF) for the first 28 DIM in accordance with results published by Bareille et al. (2003) and NO for the remaining DIM. When no information on calving difficulty was available, an unknown calving difficulty level (UNKN) was assigned for the first $28 \mathrm{DIM}$ and NO for the remaining DIM. If a MEC or MY measurement for a milking was missing, the MEC or MY, respectively, for the next milking was not included in the analysis. Day in milk, $\mathrm{DIM} \times \mathrm{DIM}$, and WF were entered as quantitative variables. Random by cow ID statement was used to allow for random intercept, DIM, and DIM $\times$ DIM estimate for each cow. The following represents the full model of the effect of health events on MY or MEC:

$$
\begin{gathered}
\mathrm{Y}_{\mathrm{ijklmno}}=\mathrm{INT}+\mathrm{DRD}_{\mathrm{ij}}+\mathrm{ID}_{\mathrm{k}}+\mathrm{DIFF}_{1}+\mathrm{PAR}_{\mathrm{m}} \\
+\mathrm{BST}_{\mathrm{n}}+\mathrm{CALF}_{\mathrm{o}}+\beta_{1} \mathrm{DIM}+\beta_{2} \mathrm{DIM} \times \mathrm{DIM} \\
+\beta_{3} \mathrm{WF}+\varepsilon_{\mathrm{ijklmno}},
\end{gathered}
$$

where $\mathrm{Y}_{\mathrm{ijk} k \mathrm{knn}}=\mathrm{MEC}$ or MY for each milking; INT = intercept; $\mathrm{DRD}=$ day relative to day of breeding or health event i; ID = cow; DIFF $=$ calving difficulty; $\mathrm{PAR}=$ lactation number; $\mathrm{BST}=$ day relative to somatotropin treatment; $\mathrm{CALF}=$ number of calves in current lactation; DIM = day of lactation; WF = weather factor calculated for each calendar day; and $\varepsilon$ $=$ residual error.

\section{Modeling MY and MEC of Healthy Animals}

To model MY at each milking, all cow-days that exhibited a significant decrease in MY, based on the mixed model described above, were eliminated from

Table 2. Description of class variable levels used when modeling effect of health events on milk yield and electro-conductivity

\begin{tabular}{ll}
\hline Variable & Level \\
\hline All health events (mild mastitis, moderate mastitis, severe mastitis, udder edema, udder scald, & $-10 \mathrm{~d},-9 \mathrm{~d},-8 \mathrm{~d},-7 \mathrm{~d},-6 \mathrm{~d},-5 \mathrm{~d}$, \\
udder related, ketosis, off feed, other digestive disorders, milk fever, displaced abomasum, & $-4 \mathrm{~d},-3 \mathrm{~d},-2 \mathrm{~d},-1 \mathrm{~d}, 1 \mathrm{~d}, 2 \mathrm{~d}, 3 \mathrm{~d}$, \\
pneumonia, other diseases, hoof treatment, lameness, injury, abscess, uterine infections, & $4 \mathrm{~d}, 5 \mathrm{~d}, 6 \mathrm{~d}, 7 \mathrm{~d}, 2 \mathrm{wk}, 3 \mathrm{wk}, 4 \mathrm{wk}$, \\
reproductive disorders, metritis, endometritis, cystic cow, vaccinations, & $5 \mathrm{wk}, 6 \mathrm{wk}, 7 \mathrm{wk}$, and NOEVENT \\
other reproductive disorders, procedure) and breeding & $1 \mathrm{~d}, 2 \mathrm{~d}, 3 \mathrm{~d}, 4 \mathrm{~d}, 5 \mathrm{~d}, 6 \mathrm{~d}, 7 \mathrm{~d}$, \\
Somatotropin treatment & $8 \mathrm{~d}, 9 \mathrm{~d}, 10 \mathrm{~d}, 11 \mathrm{~d}, 12 \mathrm{~d}, 13 \mathrm{~d}, 14 \mathrm{~d}$, and NOTREAT \\
& $1,2,3$, and $\geq 4$ \\
Parity & 1 and 2 \\
Number of calves & NO, DIFF, and UNKN \\
Calving difficulty &
\end{tabular}


data set 1 . This procedure eliminated $13 \%$ of original data set 1 data. The GLM procedure of SAS was applied to the resulting data set to model the effect of parity ( 1 and $>1$ ), and MY at previous milkings (lag1, lag2, lag3, and lag4) on current MY.

To model MEC at each milking, all cow-days that exhibited a significant decrease in MEC, based on the mixed model described above, were eliminated from data set 1 . This procedure eliminated $7 \%$ of original data set 1 data. Electrical conductivity at current milking was the response and readings from previous milkings (up to lag4) and parity were the predictors. Only significant terms were kept in the model.

\section{Designing a Health Monitoring Scheme}

Two different health monitoring schemes were developed: scheme SPC-MY identified cows with potential health problems based on individual MY; scheme SPC-MY/MEC identified cows with potential health problems based on individual MY and MEC. Residuals obtained from the MY and MEC models developed by the GLM procedure were used to develop a self-starting, head start, winsorized CUSUM chart for location and scale, and a self-starting Shewhart chart. Terms relating to the SPC charts are briefly explained below. For further details, please refer to Hawkins and Olwell (1998).

The term self-starting chart implies that, at the onset of the monitoring period, the mean is set to 0 and the variation to 1 . As data are accumulated both mean and variation are updated by calculating a running mean and running variation. Upward $\left(\mathbf{S}^{+}\right)$and downward $\left(\mathbf{S}^{-}\right)$CUSUM for the self-starting mean chart (location CUSUM) are calculated as presented below (Hawkins and Olwell, 1998):

$$
\begin{aligned}
& S_{n}^{+}=\max \left(0, S_{n-1}^{+}+U_{n}-k\right) \\
& S_{n}^{-}=\max \left(0, S_{n-1}^{-}-U_{n}+k\right),
\end{aligned}
$$

where $2 \times k$ is the shift in mean that the location CUSUM is optimized to detect, $U_{n}$ is the inverse normal of the Student's $t$ distribution with parameters $F_{n-2}\left(a_{n} T_{n}\right)$, where

$$
a_{n}=\sqrt{\frac{n-1}{n}}, T_{n}=\frac{X_{n}-\bar{X}_{n-1}}{S_{n-1}}, S_{n}^{2}=\frac{W_{n}}{n-1},
$$

and $\bar{X}$ and $W_{n}$ are the running mean and standard deviation of the residuals.
The upward $\left(\mathbf{V}^{+}\right)$and downward $\left(\mathbf{V}^{-}\right)$CUSUM for the self-starting variation chart (scale CUSUM) are calculated as follows (Hawkins and Olwell, 1998):

$$
\begin{aligned}
& V_{n}^{+}=\max \left(0, V_{n-1}^{+}+U_{n}^{2}-r\right) \\
& V_{n}^{-}=\max \left(0, V_{n-1}^{-}-U_{n}^{2}+r\right),
\end{aligned}
$$

where $r$ is the reference value determined by the size of shift in variation that the scale CUSUM is optimized to detect.

The reference values $(k, r)$ can be obtained from software provided by Hawkins and Olwell (http://www. stat.umn.edu/cusum/software.htm). After specifying the mean or variation and the size of shift (in mean or variation), the software returns the $k$ or $r$ value, respectively. Then, the $\mathrm{S}^{+}$and $\mathrm{S}^{-}$values are plotted on a location CUSUM. The $\mathrm{V}^{+}$and $\mathrm{V}^{-}$values are plotted on a scale CUSUM. To identify when the mean or variation has shifted from the specified values, UCL and LCL are plotted on the charts. The UCL and LCL can also be obtained from the mentioned software and are determined by the chosen average time to a false signal for each of the charts. The greater the desired average time to a false signal the wider the limits.

Head start implies that the initial values $\left(S_{0}^{+}, S_{0}^{-}, V_{n}^{+}\right.$, and $\left.V_{n}^{-}\right)$are set not at the mean, but halfway between the mean and UCL or LCL. This sensitizes the chart to detecting changes at the onset of charting, which, in this study, is the onset of lactation. The influence of potential outliers or extreme values on the mean and variation estimates was minimized by setting a winsorizing constant (w; Hawkins and Olwell, 1998). In this procedure, whenever $U_{n}$ calculated based on the residuals is $<-\mathrm{w}$ or $>\mathrm{w}$ it is replaced by the value of $-\mathrm{w}$ or $\mathrm{w}$, respectively. The corrected value of the residual is then back-calculated from the value of $U_{n}=-\mathrm{w}$ or $\mathrm{w}$, and replaces the actual residual in the calculations of the running mean and variation. To address the problem of greater variation in MY at the onset of lactation, $\mathrm{w}$ for MY charts was set to 0.5 for the first 7 DIM and 3 for the remaining DIM. Winsorizing constant was set at 3 for all DIM in case of MEC charts.

The self-starting Shewhart chart is obtained by plotting the $U_{n}$ values on a chart with a mean 0 , UCL set at 3 , and LCL set at -3 .

For each of the 2 schemes (SPC-MY and SPC-MY/ MEC), 3 monitoring options were designed to result in approximately 98,99 , or $99.5 \% \mathrm{Sp}$. This was achieved by adjusting the size of shift (in mean or variation) the 
CUSUM charts were optimized for, the average time to false signal on the CUSUM charts, and the number of signals that were necessary for an alarm to be issued. The CUSUM scale chart issued a signal whenever a point was plotted above the UCL; and the CUSUM location chart issued a signal whenever a point on the MY chart was plotted below LCL or a point plotted on the MEC chart was above UCL. To give greater attention to large shifts in mean, 3 signals were issued whenever a point plotted on the Shewhart chart was below the LCL on the MY monitoring chart or above the UCL on the MEC monitoring chart. The procedure was performed for each cow separately resulting in 6 SPC charts, 3 for MY (CUSUM for location, CUSUM for scale, and Shewhart chart) and 3 for MEC, per animal. Monitoring scheme SPC-MY considered only MY charts (3 charts per animal). Monitoring scheme SPC-MY/MEC considered both MY and MEC charts (6 charts per animal). In all developed monitoring schemes the number of signals occurring within 3 milkings was summarized. To avoid repeated signals for an already diagnosed disease, all signals were suppressed for $7 \mathrm{~d}$ whenever a disease was diagnosed. An attempt was made to incorporate the information on prior MY and MEC distribution into the current year monitoring scheme. To achieve this objective, an MY and MEC mean and SD was calculated for the first $3 \mathrm{wk}$ of lactation from the milk records of healthy animals (i.e., those not experiencing any health events within the first 100 DIM). This was done separately for firstlactation, second-lactation, and older cows. For each of these lactation groups, a separate MY mean and SD was calculated for cows calving between April and October (low season) and between November and March (high season). This resulted in 6 means and $6 \mathrm{SD}$ for $\mathrm{MY}$ and 3 means and 3 SD for MEC. A random number generator in SAS was used to generate $42 \mathrm{MY}$ readings for each of the 6 distributions (first, second, third+ lactation, and high and low season) and 42 MEC readings from each of the 3 distributions (first, second, third+ lactation). The generated data were labeled cohortbased. Generated cohort-based data were placed before each cow's current lactation according to her lactation number (for MEC) or lactation number and season of calving (for MY). For example, a first-lactation cow calving in March 2006 would have 42 cohort-based readings from the first lactation, high season distribution of MY, and 42 cohort-based readings from the first lactation MEC distribution assigned before her date of calving. With the self-starting approach used in the monitoring schemes, the initial mean and SD were set to 0 and 1 , respectively. However, the 42 cohort-based readings were used to calculate the running mean and SD. Therefore, when real data began to be collected and cow monitoring was initiated, the running mean and SD were already adjusted for the lactation and season of calving.

\section{Evaluation of the Health Monitoring Schemes}

Herd management used the DairyPlan (DP) scheme as an on-farm disease detection system. The schemes designed in this study were compared with the DP. The performance of the monitoring scheme was evaluated based on the ability of the monitoring scheme to detect disease before or on the day of diagnosis $(\mathrm{Sn})$ and the rate of false positive alarms (FPR) during the first 100 DIM. Data set 2 was used for the evaluation. In data set 2 , health events were recorded by date (not by milking), therefore, disease diagnosis was assigned to the whole day (2 milkings). For all Sn and Sp calculations, true status was determined daily by disease diagnosis record. The true status of a cow not diagnosed with any disease within the next $10 \mathrm{~d}$ was considered disease negative $\left(\mathrm{D}^{-}\right)$for that particular day. False positive rate was calculated for all health episodes together. Sensitivity was estimated separately for 4 disease groups. Group 1 contained udder related health problems (mastitis, edema, udder scald and other udder related). Group 2 contained digestive and metabolic disorders (left displaced abomasum, ketosis, milk fever, off feed, other digestive). Group 3 consisted of reproductive health problems (metritis and retained placenta). Pneumonia, lameness, abscess, and other diseases constituted group 4. For the SPC and DP schemes, 1 true positive was declared whenever a health alarm occurred within a 10-d period preceding or on the day of diagnosis of a health episode. Regardless of the number of health alarms only 1 true positive could be declared per health event. Each true positive could only be a true positive of 1 disease diagnosis. Therefore, in data set 2, if a cow was diagnosed multiple times during a $10-d$ period only the first disease diagnosis was considered. False positive was declared for each health alarm issued when no health episode occurred the day of the alarm or on the $10 \mathrm{~d}$ following the alarm. Sensitivity was calculated as the number of true positive results divided by the number of health episode occurrences. False positive rate was calculated as the number of false positive alarms per $100 \mathrm{D}^{-}$cows. Specificity was calculated from the FPR $(\mathrm{SP}=100-\mathrm{FPR})$.

Logistic regression was used to compare the Sn and Sp of the designed monitoring schemes to that offered by the DP scheme. The difference in Sn between the DP scheme and the developed schemes was tested by modeling the probability of a health alarm being issued using the subset of cow-days when disease from a specific group was diagnosed (Dohoo et al., 2003) 
and entering the variable scheme as a dependent. The difference in Sp between the DP scheme and the developed schemes was tested by modeling the probability of a health alarm not being issued, using a subset of data without all of cow-days when a disease was diagnosed and without the $10 \mathrm{~d}$ before that date, and entering the variable scheme as a dependent. The variable scheme was a categorical variable with the following 7 levels: DP, SPC-MY-98, SPC-MY-99, SPC-MY-99.5 (designed scheme based on MY, with a target Sp of 98,99 , and 99.5\%, respectively), SPC-MY/MEC-98, SPC-MY/ MEC-99, and SPC-MY/MEC-99.5 (designed scheme based on MY and MEC, with a target Sp of 98, 99, and $99.5 \%$, respectively).

\section{RESULTS AND DISCUSSION}

\section{Effect of Health Events and Other Factors on MY and MEC}

Milk Production. The effects of health events on MY are summarized in Table 3. Miscellaneous digestive disorders (represented mainly by diarrhea) and udder scald had the greatest negative cumulative effect on MY (-304.42 and $-304.17 \mathrm{~kg}$, respectively) over the whole period when the effect was significant (Table 3 ). The greatest average daily effect was estimated for milk fever $(-10.36 \mathrm{~kg})$. Milk fever had also the greatest single day effect of $-24.10 \mathrm{~kg} 1 \mathrm{~d}$ before diagnosis (data not presented). Milk fever was usually diagnosed within the first 2 DIM limiting the number of available records prediagnosis. Therefore, the effect estimate for day before day of diagnosis, although significant, has to be considered with some caution, because it is based on a limited number of records. Several udder disorders had a long-lasting effect on MY: mild (53 d) and moderate $(51 \mathrm{~d})$ mastitis, udder scald $(58 \mathrm{~d})$, and other udder-related disorders $(50 \mathrm{~d})$. Pneumonia, left displaced abomasums, retained placenta, miscellaneous digestive disorders, and other disorders also had a longlasting effect of $58,54,51,57$, and $56 \mathrm{~d}$, respectively. Bareille et al. (2003) demonstrated the greatest initial negative effect of $-25.7 \mathrm{~kg} 3 \mathrm{~d}$ before the day of diagnosis for milk fever. They also reported the greatest total effect of -155 and $-160 \mathrm{~kg}$ for teat injury and systemic mastitis, respectively. The estimates are similar to those made in this study, although the effect of other udder-related problems that included teat injury in this study was estimated to be twice that reported by Bareille et al. (2003). Seegers et al. (2003) observed a $375-\mathrm{kg}$ reduction in milk yield per case of mastitis. Wilson et al. (2004) estimated the total effect of mastitis on milk yield to be $>600 \mathrm{~kg}$. The effect of edema, which in this data set was estimated at $-141.09 \mathrm{~kg}$, was estimated at $-10 \mathrm{~kg}$ by Bareille et al. (2003). The magnitude of the effect of any health disorder is likely to be affected by time from disease initiation to day of diagnosis and treatment, the time from initiation of treatment to resolution of clinical symptoms, type of specific pathogen causing the disease, herd production level, season, and stage of lactation when disease was diagnosed (Huijps et al., 2008). Therefore, the possibility of comparisons of the magnitude and length of the effect between farms and studies is limited.

Interestingly, cystic cows in our study produced 3.69 $\mathrm{kg} / \mathrm{d}$ more milk throughout the entire period considered $(-10 \mathrm{~d}$ to $49 \mathrm{~d})$. These results are supported by Loeffler et al. (1999) who demonstrated a negative relationship between milk yield and cow fertility.

Electrical Conductivity. Electrical conductivity of milk is used most commonly as an indicator of mastitis infection (Nielen et al., 1992; Woolford et al., 1998; Norberg et al., 2004). In this study, the mean MEC among healthy cows was 490 reference units (SD 58.1). Significant increases reported in Table 4 ranged from 10.4 to 40.8 reference units, which corresponds to 2.1 and $8.2 \%$, respectively. Woolford et al. (1998) reported greater values of 11.8 to $32.1 \%$ increase in MEC depending on the pathogen causing mastitis infection. In the current study, MEC was monitored on the farm to help identify mastitis infections. It is therefore possible that mastitis treatment was initiated earlier in the disease process and thus the magnitude of MEC shift was decreased. Results presented in Table 4 demonstrate a significant increase in MEC of milk as early as 3 $\mathrm{d}$ before detection of mild mastitis. Among all udder health problems, the longest increase in MEC was observed in cows with mild mastitis ( $d-3$ to $d \geq 49)$ and the increase was most profound in cows with udder scald (5.7\%). Considering all disorders, milk fever was associated with the greatest increase in MEC (8.3\%). Increase in MEC was observed the longest for cows diagnosed with pneumonia $(\mathrm{d}-7$ to $\mathrm{d} \geq 49$ ). Other metabolic and digestive problems such as ketosis, off feed, left displaced abomasums, as well as retained placenta, lameness, and other diseases were also associated with a significant increase in MEC. The concept that other diseases might affect MEC has previously been suggested (de Mol, 2000). Changes in body temperature and milk fat content observed in association with some diseases might constitute the basis for such a concept. Milk temperature, which affects MEC (Prentice, 1972; Nielen et al., 1992), is also sensitive to changes in body temperature. Decrease in milk fat is observed in cows that are off feed, experiencing acidosis (Kleen et al., 2003), fatty liver, ketosis, and displaced abomasa (Nordlund and Cook, 2004). A decrease in milk fat was also reported before hoof treatments (Nishimori et al., 2006) 
Table 3. Effect of specific health events ${ }^{1}$ on milk production ${ }^{2}$

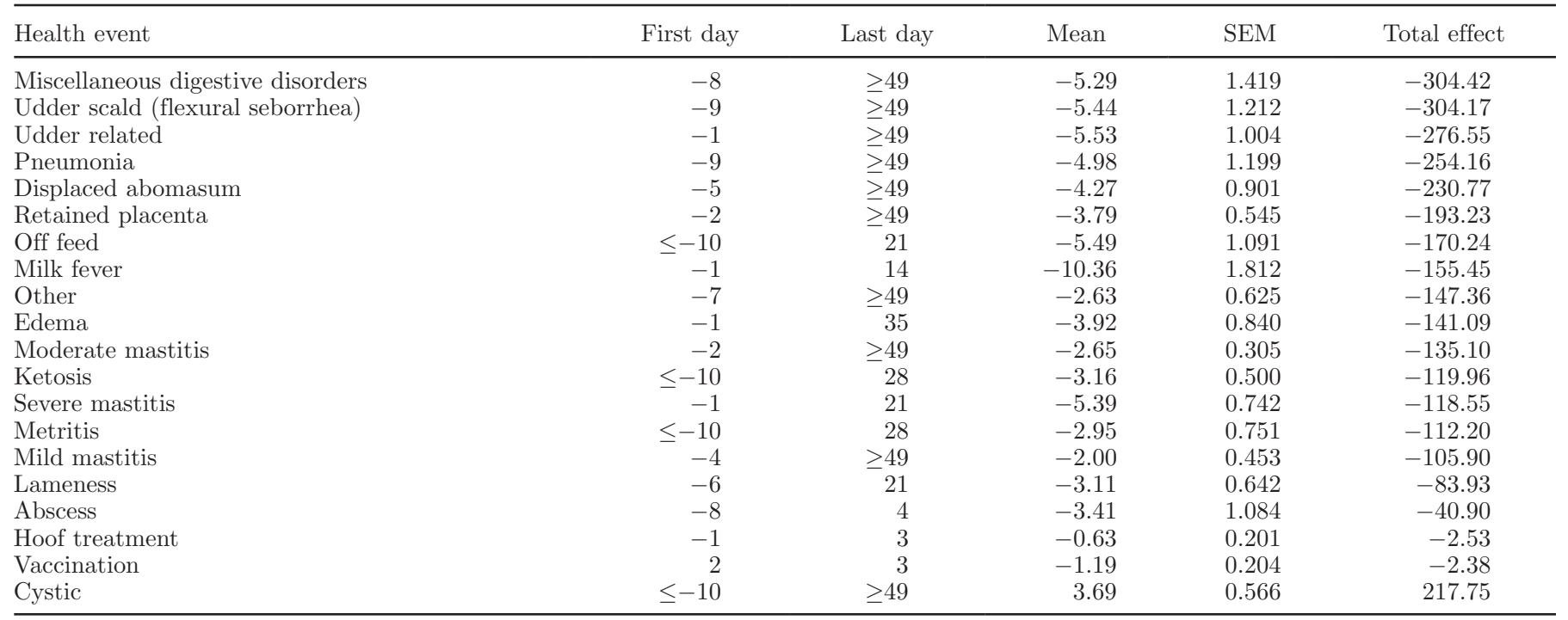

${ }^{1}$ The term health events used in this study refers to diseases experienced by the animals, administered vaccinations, and other procedures.

${ }^{2}$ Presented are the results of modeling milk production, standardized for a 24 -h period, using a mixed model. Each health event had 24 levels representing day relative to day of occurrence, with 1 level per day ( $\mathrm{d}-10$ to $\mathrm{d} 7$ ), 1 level per week ( 8 to d 49), and 1 level for all days outside the event period. First and last day represent the first and last day of significant parameter estimate of the mixed model. Effects with no significant parameter estimates for any of the levels were not included in the table.

and is most probably related to developing lameness problems. Decrease in milk fat increases MEC (Woolford et al., 1998) and might contribute to the results observed in this study.

Other Factors. Electrical conductivity increased by 0.18 with each DIM $(P<0.0001)$. Factor DIM $\times$ DIM was only significant in the milk yield model $(-0.00039$; $P<0.0001$ ). Weather (WF) was a significant factor in both models. An increase of $1^{\circ} \mathrm{C}$ resulted in a 0.018 $\mathrm{kg} / 24 \mathrm{~h}(P<0.0001)$ decrease in MY and 0.011 increase in MEC $(P=0.0248)$. West (2003) also reported decreased milk yield with an increase in ambient temperature. Milk electrical conductivity increases linearly with milk temperature (Prentice, 1972; Henningsson et al., 2005). Milk temperature has been reported to increase linearly with ambient temperature (West, 2003),

Table 4. Effect of specific health events ${ }^{1}$ on milk electrical conductivity ${ }^{2}$

\begin{tabular}{lcccc}
\hline Health event & First day & Last day & Mean & SE \\
\hline Milk fever & 1 & 3 & 40.8 & 11.47 \\
Displaced abomasum & -2 & 1 & 38.3 & 20.53 \\
Udder scald (flexural seborrhea) & -3 & 14 & 28.1 & 10.08 \\
Pneumonia & -7 & $\geq 49$ & 27.2 & 8.29 \\
Off feed & -6 & 5 & 26.0 & 11.40 \\
Udder related & -2 & 42 & 25.4 & 10.08 \\
Edema & -3 & 14 & 24.9 & 9.13 \\
Other & -2 & 1 & 19.7 & 5.53 \\
Severe mastitis & -1 & 14 & 17.1 & 6.21 \\
Lameness & -1 & 5 & 15.8 & 5.85 \\
Mild mastitis & -3 & $\geq 49$ & 12.0 & 3.83 \\
Retained placenta & -2 & 21 & 12.0 & 4.54 \\
Ketosis & -9 & 1 & 11.8 & 4.45 \\
Moderate mastitis & -1 & 28 & 10.4 & 2.55 \\
\hline
\end{tabular}

${ }^{1}$ The term health events used in this study refers to diseases experienced by the animals, administered vaccinations, and other procedures.

${ }^{2}$ Presented are the results of modeling milk electrical conductivity using a mixed model. Each health event had 24 levels representing day relative to day of occurrence, with 1 level per day ( $d-10$ to $d 7$ ), 1 level per week (d 8 to d 49), and 1 level for all days outside the event period. First and last day represent the first and last day with a significant positive estimate of the mixed model. Effects with no significant parameter estimates for any of the levels were not included in the table. 
Table 5. Healthy ${ }^{1}$ cow milk yield model $^{2}$

\begin{tabular}{lrcc}
\hline Parameter & Estimate & SE & $P$-value \\
\hline Intercept & 1.41 & 0.023 & $<0.001$ \\
Milk/24 h lag 1 & 0.96 & 0.002 & $<0.001$ \\
Milk/24 h lag 2 & -0.43 & 0.002 & $<0.001$ \\
Milk/24 h lag 3 & 0.53 & 0.002 & $<0.001$ \\
Milk/24 h lag 4 & -0.10 & 0.002 & $<0.001$ \\
Parity 1 & -0.15 & 0.011 & $<0.001$ \\
\hline
\end{tabular}

${ }^{1}$ Not diagnosed with any diseases for the first 100 DIM.

${ }^{2}$ Presented are the results of a linear model of current milk yield over $24 \mathrm{~h}$ using a subset of healthy cow records. Lag 1 represents 1 milking.

explaining the increase in MEC observed in our study. Cows having twins had lower MY $(3.39 \mathrm{~kg} / 24 \mathrm{~h} ; P<$ 0.0001). Chapin and Van Vleck (1980) have previously reported a decrease of $285 \mathrm{~kg}$ of milk per lactation in cows after a twin calving, suggesting a less extensive lobuloalveolar duct development because of shorter gestation period as one of the possible explanations. Also, Nielen et al. (1989) reported that cumulative MY during lactation of cows after a twin calving was $291 \mathrm{~kg}$ less than that in singletons. Cows with known greater calving difficulty produced less milk $(-4.05 \mathrm{~kg} / 24 \mathrm{~h}$; $P<0.0001)$, and had lower MEC $(13.95 ; P<0.0001)$. Lower MY associated with greater calving difficulty might have resulted in more concentrated milk with greater fat content. The greatest MY was estimated for cows in the second lactation $(7.77 \mathrm{~kg} / 24 \mathrm{~h}$ more than cows in the fourth lactation; $P<0.0001)$. Electrical conductivity was lowest for cows in the first lactation (36.24 units less than cows in the fourth lactation; $P<$ 0.0001). Observations made by Sheldrake et al. (1983) reporting an increase in MEC in subsequent lactations support the results observed.

\section{Monitoring Scheme}

Performance of SPC charts is sensitive to lack of independence between subsequent observations (Hawkins and Olwell, 1998). When, in a normally operating process, a value above the mean tends to be followed by another value above the mean and vice versa (positive autocorrelation), the $\mathrm{S}^{+}$or $\mathrm{S}^{-}$on the CUSUM will increase or decrease, respectively, eventually crossing the UCL or LCL and issuing a false alarm. To address the problem of autocorrelation between individual cow MY and MEC readings (de Mol, 2000) an approach suggested by Montgomery (2005) was used and 2 autoregressive models were developed based on a subset of healthy cow records. Other researchers have suggested using an autoregressive model to model MY or MEC (de Mol, 2000; Macciotta et al., 2000). The resulting models are presented in Table 5 and Table 6 . In Table 5 an alternate pattern of positive and negative coefficient estimates for odd and even lags can be observed. This pattern is related to the autocorrelation introduced by standardization of milk yield for a 24 -h period for each milking (de Mol 2000). In Table 6 a higher coefficient is estimated for even-numbered lags. In the model, 1 lag refers to 1 milking; therefore, even-numbered lags refer to milkings of the same time of day (a.m. or p.m.) as the estimated milking. Electroconductivity is known to vary depending on the time of milking (a.m. or p.m.). Therefore, it can be expected that MEC at current milking is more strongly correlated to milkings represented by even-numbered lags and less correlated to milkings represented by odd-numbered lags. The models developed in this study were used to obtain residuals for all cows $\left(\mathrm{D}^{-}\right.$and $\left.\mathrm{D}^{+}\right)$and the residuals were then plotted on CUSUM and Shewhart charts of the 6 monitoring schemes (SPC-MY-98, SPC-MY-99, SPC-MY-99.5, SPC-MY/MEC-98, SPC-MY/MEC-99 and SPC-MY/MEC-99.5).

The results of the logistic regression model comparing $\mathrm{Sn}$ and $\mathrm{Sp}$ between all the designed schemes and the DP scheme are presented in Table 7. When Sp of the designed schemes was set to be similar to the DP scheme (SPC-MY-98 and SPC-MY/MEC-98), the Sn of detection of udder, metabolic, and reproductive health problems was 2 to 6 times greater than that observed for the DP scheme. With FPR reduced by half (SPC-MY-99 and SPC-MY/MEC-99), Sn for udder and reproductive health events was significantly

Table 6. Healthy ${ }^{1}$ cow milk electric conductivity model ${ }^{2}$

\begin{tabular}{lccc}
\hline Parameter & Estimate $^{3}$ & SE & $P$-value \\
\hline Intercept & 39.180 & 0.6648 & $<0.001$ \\
Electrical conductivity lag 1 & 0.175 & 0.0020 & $<0.001$ \\
Electrical conductivity lag 2 & 0.371 & 0.0021 & $<0.001$ \\
Electrical conductivity lag 3 & 0.113 & 0.0021 & $<0.001$ \\
Electrical conductivity lag 4 & 0.263 & 0.0020 & $<0.001$ \\
Parity 1 & -2.421 & 0.1379 & $<0.001$ \\
\hline
\end{tabular}

${ }^{1}$ Not diagnosed with any diseases for the first 100 DIM.

${ }^{2}$ Presented are the results of a linear model of current electric conductivity using a subset of healthy cow records. Lag 1 represents 1 milking.

${ }^{3}$ Electric conductivity expressed in reference units (500 reference units $\approx 6 \mathrm{mS}$ ). 
Table 7. Sensitivity (Sn) and false positive rate (FPR) of the monitoring schemes ${ }^{1}$

\begin{tabular}{lccccc}
\hline & & \multicolumn{4}{c}{$\mathrm{Sn}^{5}$} \\
\cline { 3 - 6 } Model $^{2}$ & $\begin{array}{c}\mathrm{FPR}^{3} \\
\left(\mathrm{n}=4,5164^{4}\right)\end{array}$ & $\begin{array}{c}\text { Udder } \\
\left(\mathrm{n}=54^{6}\right)\end{array}$ & $\begin{array}{c}\text { Metabolic } \\
\left(\mathrm{n}=24^{6}\right)\end{array}$ & $\begin{array}{c}\text { Repro } \\
\left(\mathrm{n}=31^{6}\right)\end{array}$ & $\begin{array}{c}\text { Other } \\
\left(\mathrm{n}=47^{6}\right)\end{array}$ \\
\hline DP & 97.9 & 22.2 & 20.8 & 9.7 & 23.4 \\
SPC-MY-98 & $98.0 \dagger$ & $44.4^{*}$ & $45.8^{\dagger}$ & $48.4^{* *}$ & 23.4 \\
SPC-MY-99 & $99.0^{* * *}$ & $42.6^{*}$ & 37.5 & $48.4^{* *}$ & 17.0 \\
SPC-MY-99.5 & $99.5^{* * *}$ & $38.9^{*}$ & 25.0 & $48.4^{* *}$ & 12.8 \\
SPC-MY/MEC-98 & 98.0 & $48.1^{* *}$ & $58.3^{*}$ & $58.1^{* * *}$ & 25.5 \\
SPC-MY/MEC-99 & $99.1^{* * *}$ & $40.7^{*}$ & 33.3 & $51.6^{* *}$ & 19.1 \\
SPC-MY/MEC-99.5 & $99.5^{* * *}$ & 25.9 & 29.2 & 16.1 & 10.6 \\
\hline
\end{tabular}

${ }^{1}$ Presented are the results obtained by logistic regression by modeling probability of no alarm on a subset of cow-days with no health event (FPR), or modeling the probability of an alarm on a subset of cow-days with a health event (Sn) from a specific group (udder, metabolic, reproductive, other).

${ }^{2} \mathrm{DP}=$ DairyPlan (WestfaliaSurge Inc., Naperville, IL); SPC-MY-98, SPC-MY-99, SPC-MY-99.5 = statistical process control designed schemes based on milk yield (MY), with a target specificity (Sp) of 98, 99, and 99.5\%, respectively; SPC-MY/MEC-98, SPC-MY/MEC-99, and SPC-MY/MEC-99.5 = designed schemes based on MY and milk electrical conductivity (MEC), with a target Sp of 98, 99, and 99.5\%, respectively.

${ }^{3} \mathrm{FPR}$ was calculated for all health events combined as the number of cows signaled by the system that were not diagnosed with any disease the day of alarm or over the $10 \mathrm{~d}$ following the alarm. Indicated probabilities refer to the significance in differences between the DP and the design schemes.

${ }^{4}$ Number of records used for estimation.

${ }^{5}$ Sensitivity was estimated for 4 health event groups (udder, metabolic, reproductive, other) separately. Indicated probabilities refer to the significance in differences between the DP and the design schemes.

${ }^{6}$ Number of health episode occurrences.

${ }^{* * *} P<0.001 ;{ }^{* *} P<0.01 ;{ }^{*} P<0.05 ; \dagger P<0.1$.

greater and Sn for metabolic problems was numerically greater than that of the DP scheme. When the FPR was reduced by a factor of 4 (SPC-MY-99.5 and SPCMY/MEC-99.5), Sn of udder, metabolic, and reproductive disorders was still numerically greater than the estimates for the DP scheme. With FPR $=0.5$, only 1 significant difference (SPC-MY-99.5 for reproductive disease detection) and 1 tendency (SPC-MY-99.5 for udder disease detection) were observed. Although numerical differences are evident and mostly in favor of the DP scheme, the small prevalence of the remaining health problems (other diseases group) determined the lack of significant differences in Sn estimates between the DP and the designed schemes.

Potential bias introduced by the fact that DP was used on the study farm to identify animals experiencing health problems might have led to overestimation of both Sn and Sp for the DP scheme. It has to be noted, however, that DP, as well as animal observation and regular veterinary checks, was one of the indicators of potential disorders and that final diagnosis (true status determination) was always made based on an examination by a veterinarian. A multi-farm study, comparing several already developed models with the SPC schemes presented in this study would be necessary to fully evaluate the performance of the SPC schemes. However, some reference to studies of other researchers attempting to develop a disease detection model might help put our results in some perspective. de Mol et al. (2001) developed a multivariate mastitis and estrus detection model based on MY, MEC, milk temperature, and animal activity. Field performance test of the model revealed that with Sp at 98.1 or $99.4 \%$ the model was capable of detecting 59 or $36 \%$ of clinical mastitis cases, respectively. Norberg et al. (2004) monitored different quarter milk MEC measures for individual cows demonstrating clinical mastitis detection Sp between 91.9 and $98 \%$, with Sn estimated at 47.9 and $16.2 \%$, respectively.

For all health events, the number of health alarms issued by the SPC-MY/MEC-98 and the DP scheme was noted and summarized by day relative to day of diagnosis in Figure 1. Average daily MY and MEC were calculated for the $10 \mathrm{~d}$ before diagnosis of any health event Figure 2. For all days, the number of health alarms issued by SPC-MY/MEC-98 was greater and more alarms were issued earlier relative to the day of diagnosis. Similar health alarm patterns were observed for the remaining 5 schemes developed in this study (data not presented). An increase in the number of health alarms issued by DP and SPC-MY/MEC-98 was observed $8 \mathrm{~d}$ before day of diagnosis; however, the number of alarms was greater for the SPC-MY/MEC-98 scheme. Table 3 suggests that these are not false alarms and that they are issued in response to a decrease in MY observed on d -8 relative to day of diagnosis. Figure 2 also demonstrates an interesting relationship between MY and MEC on several days preceding a health event. Each marked decrease in MY (d $-8,-6,-4$, and -2 to 0$)$ is associated with a decrease in MEC. As previously 


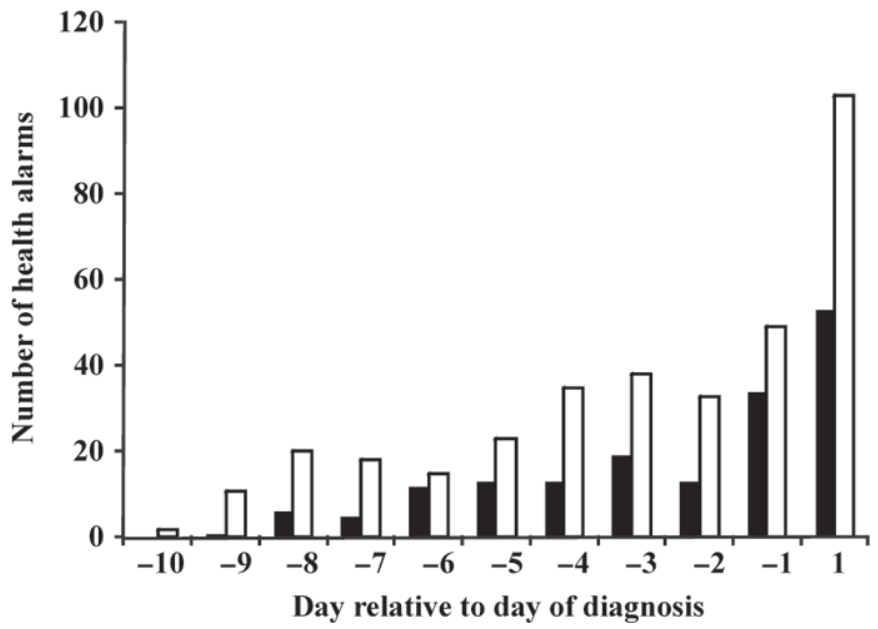

Figure 1. Number of health alarms issued by one of the design monitoring schemes (SPC-MY/MEC-98, where SPC = statistical process control; $\mathrm{MY}=$ milk yield; $\mathrm{MEC}=$ milk electrical conductivity) and the software used on the farm (DP, DairyPlan, WestfaliaSurge, Naperville, IL) relative to the day of health event diagnosis. Solid black bars represent number of health alarms issued by the DP scheme white bars represent the designed scheme (SPC-MY/MEC-98). Day 1 marks the day of health event diagnosis.

suggested, a decrease in MY might result in an increase in the fat content of milk and subsequently decrease MEC in the $\mathrm{D}^{+}$cows.

Although the decrease in MY from d -2 to d 1 appears linear, the downward shifts on $\mathrm{d}-8$ and -4 are followed by a day of increased MY, making the changes in MY from $\mathrm{d}-8$ to -3 more subtle. The combination of both CUSUM and Shewhart charts used in the monitoring schemes developed in this study resulted in Sn to both lesser as well as greater changes in MY. The subtle character of the changes in MY observed from d -8 to $\mathrm{d}-3$ might reflect the allostatic response during the subclinical phase of an adverse health event until the cow's adaptive capacity is overwhelmed (Colditz, 2002; Beerda et al., 2004, 2007). Nocek (1997) reports that subclinical acidosis is associated with more subtle changes and inconsistencies in MY. Observations made by Lucey et al. (1986) suggest that if individual cow MY data were available for each animal on a daily basis, subclinical diseases could be detected 2 or more weeks before observation of clinical signs. Similarly, Duffield (2000) states that subtle decreases in MY can be characteristic of subclinical ketosis, and Mungube et al. (2005) demonstrate a $17 \%$ loss of MY in quarters subclinically infected with mastitis. In diseases such as Johne's, the presence of an initial immune response has been demonstrated before clinical signs of the disease appear (Bannantine et al., 2008). Detection of the disease at this stage is critical in the attempt to decrease its effect on herd health. Milner et al. (1997) demonstrated a lesser effect of mastitis on MY, SCC, and antibiotic treatment duration when treatment was initiated based on changes in MEC, before clinical signs of mastitis were observed.

As mentioned previously, the designed SPC-MY and SPC-MY/MEC schemes issue more true positive health alarms and issue them earlier relative to the day of diagnosis making them more sensitive and timely than the scheme currently used on the farm (DP). Earlier alerts of an emerging health problem offer the potential of earlier diagnosis. Earlier treatment can potentially decrease duration and severity of the problem and significantly reduce MY losses. In some cases, however, when disease alerts are issued several days before diagnosis, disease-specific clinical signs might not be observable when the monitoring system first issues an alert. Depending on the Sp of the chosen scheme, the herd manager can be certain that 98 to $99.5 \%$ of $\mathrm{D}^{-}$cows will not be flagged by the warning system. As demonstrated in Figure 2, between $\mathrm{d}-9$ and $\mathrm{d}-3$ cows struggle to maintain their MY while trying to cope with the stress factors that are affecting them. Intervention at this point might not require any disease specific treatment. Although closer monitoring of the affected cows should be considered, the herd manager should focus on eliminating the stressing factors in the management environment of the signaled cow or group of cows. For example, a herd manager seeing alerts issued for recently calved cows might decrease the stocking density in the postcalving pen, reducing the competition for the feed bunk or lying space. There is ample evidence that certain grouping strategies or overstocking disrupt normal cow social behavior and can reduce access to feed, water, and stall rest. This unnecessary stress can result in production losses or increase the risk of postpartum diseases (Nordlund et al.,

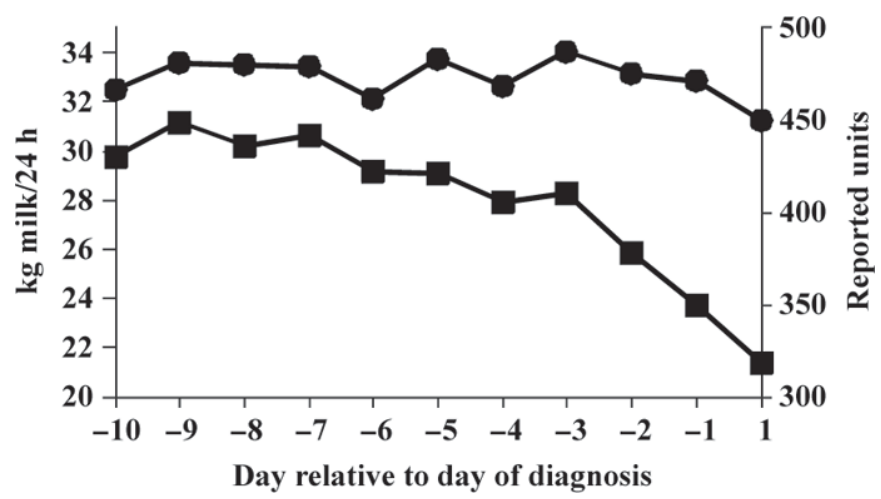

Figure 2. Milk yield (MY, $\mathbf{\square}$ ) and electrical conductivity (MEC, -) relative to day of diagnosis. Milk is reported in $\mathrm{kg} / 24 \mathrm{~h}$ per cow. Electrical conductivity is presented in units reported by the software used on the farm (500 reported units $\approx 6 \mathrm{mS}$ ). Day 1 marks the day of health event diagnosis. 
2006; Huzzey et al., 2007). Removal of environmental stressors may prevent the animals from progressing into the clinical phase of a disease and rapidly losing MY. Such a rapid decrease in MY can be observed between $\mathrm{d}-2$ to $\mathrm{d} 1$ (Figure 2).

Cohort data generated based on the prior MY and MEC distribution of cows of a specific parity and season of calving were placed before each cow's current lactation according to her lactation number and calving date. Inclusion of information on prior distribution is a common approach in Bayesian statistics (Bayarri and Garcia-Donato, 2005). Incorporating prior information into the system allows the monitoring scheme to become more farm specific when several years of data are already available. Including prior data in process analysis also provides insight into management changes of similar cohorts of cows that might occur from year to year. In larger herds, the cohorts used to provide prior distribution for cohort-based data generation can be made more specific by creating cohort groups by breed, calving seasons, or lactation number. Cows experience greater variation in MY within the first few DIM than in the remaining stages of lactation. When the self-starting approach is used for the CUSUM chart, increased variation at the onset of charting significantly reduces the $\mathrm{Sn}$ of the charts (Hawkins and Olwell, 1998). Using prior distribution information helps alleviate this problem by including prior data in the calculation of the running standard deviation. This causes the standard deviation calculation and the setting of the UCL and LCL to be less sensitive to the increased number of extreme values at the beginning of lactation. The winsorizing constant was also adjusted for the first 7 DIM $(\mathrm{w}=0.5$ and $\mathrm{w}$ $=3$ for $<8$ DIM and $>7$ DIM, respectively) to further limit the effect of extreme values on the variation estimation as recommended by Hawkins and Olwell (1998). The net effect was to increase the Sn of the health monitoring scheme during the period in lactation when more variation exists and most diseases occur.

The focus of the current study was to develop a scheme that would alert herd management to the onset of an adverse health event. The same schemes can also be used to identify the onset of recovery from a disease event. Evaluating the performance to these schemes in detecting the onset of recovery would require knowing for each case of diagnosed disease if and when the recovery began. This would require a more controlled study in which bacterial cultures (in case of mastitis), milk and blood tests (in case of metabolic diseases), or physical examination (in case of lameness and other diseases) would determine the exact day of recovery that could be recorded and used to determine the true status of the animal for the purpose of Sn and Sp analysis.

\section{CONCLUSIONS}

The current study demonstrated that significant changes in milk yield and electrical conductivity can be observed as early as $10 \mathrm{~d}$ before diagnosis of an adverse health event. By introducing the cow health monitoring schemes based on MY and MEC developed in this study, the herd manager would be alerted earlier and with twice the odds of identifying an emerging udder, reproductive, or metabolic problem than by the disease detection system currently used on the farm (DP). Signals issued by the monitoring schemes are not disease specific and do not indicate what type of disease is emerging. The signals are, however, issued up to $10 \mathrm{~d}$ before the disease enters the clinical phase, giving the herd manager a time advantage that can be used to identify and eliminate the environmental stress factors that potentially compromise the cow's ability to fight off the emerging disease. Additionally, the herd manager can provide closer monitoring of the flagged cow to ameliorate symptoms in the early stages of clinical disease before more profound biological changes occur. The possibility of choosing different FPR $(0.5,1$, and 2) and using different milk characteristics (MY only vs. MY and MEC) allows for their adoption on farms with different risk aversion attitudes as well as different availability of data.

\section{ACKNOWLEDGMENTS}

The authors express their gratitude to the always helpful technical support of WestfaliaSurge (Naperville, IL) and Dairy Records Management Systems (Raleigh, $\mathrm{NC})$.

\section{REFERENCES}

Bannantine, J. P., D. O. Bayles, W. R. Waters, M. V. Palmer, J. R. Stabel, and M. L. Paustian. 2008. Early antibody response against Mycobacterium avium subspecies paratuberculosis antigens in subclinical cattle. Proteome Sci. 6:5-17.

Bareille, N., F. Beaudeau, S. Billon, A. Robert, and P. Faverdin. 2003. Effects of health disorders on feed intake and milk production in dairy cows. Livest. Prod. Sci. 83:53-62.

Barkema, H. W., J. D. Van der Ploeg, Y. H. Schukken, T. J. Lam, G. Benedictus, and A. Brand. 1999. Management style and its association with bulk milk somatic cell count and incidence rate of clinical mastitis. J. Dairy Sci. 82:1655-1663.

Bayarri, M. J., and G. Garcia-Donato. 2005. A Bayesian sequential look at u-control charts. Technometrics 47:142-151.

Beaudeau, F., A. Henken, C. Fourichon, K. Frankena, and H. Seegers. 1993. Associations between health disorders and culling of dairy cows: A review. Livest. Prod. Sci. 35:213-236.

Beerda, B., J. E. Kornalijnslijper, J. T. N. van der Werf, E. N. Noordhuizen-Stassen, and H. Hopster. 2004. Effects of milk production capacity and metabolic status on HPA function in early postpartum dairy cows. J. Dairy Sci. 87:2094-2102.

Beerda, B., W. Ouweltjes, L. B. J. Sebek, J. J. Windig, and R. F. Veerkamp. 2007. Effects of genotype by environment interactions on milk yield, energy balance, and protein balance. J. Dairy Sci. 90:219-228. 
Chapin, C. A., and L. D. Van Vleck. 1980. Effects of twinning on lactation and days open in Holsteins. J. Dairy Sci. 63:18811886.

Colditz, I. G. 2002. Effects of the immune system on metabolism: Implications for production and disease resistance in livestock. Livest. Prod. Sci. 75:257-268.

Correa, M. T., H. Erb, and J. Scarlett. 1993. Path analysis for seven postpartum disorders of Holstein cows. J. Dairy Sci. 76:13051312 .

de Mol, R. M. 2000. Automated detection of oestrus and mastitis in dairy cows. Page 177 in Agricultural and Environmental Engineering (IMAG). Vol. PhD. Wageningen University, Wageningen, the Netherlands.

de Mol, R. M., W. Ouweltjes, G. H. Kroeze, and M. M. W. B. Hendriks. 2001. Detection of estrus and mastitis: Field performance of a model. Appl. Eng. Agric. 17:399-407.

Deluyker, H. A., J. M. Gay, L. D. Weaver, and A. S. Azari. 1991. Change of milk yield with clinical diseases for a high producing dairy herd. J. Dairy Sci. 74:436-445.

Dohoo, I., S. W. Martin, and H. Stryhn. 2003. Screening and diagnostic tests. Pages 85-121 in Veterinary Epidemiology Research. AVC Inc., Prince Edward Island, Canada.

Duffield, T. 2000. Subclinical ketosis in lactating dairy cattle. Vet. Clin. North Am. Food Anim. Pract. 16:231-253.

Edwards, J. L., and P. R. Tozer. 2004. Using activity and milk yield as predictors of fresh cow disorders. J. Dairy Sci. 87:524-531.

Godden, S. M., S. C. Stewart, J. F. Fetrow, P. Rapnicki, R. Cady, W. Weiland, H. Spencer, and S. W. Eicker. 2003. The relationship between herd rBST-supplementation and other factors with risk for removal for cows in Minnesota Holstein dairy herds. Pages 55-64 in Proc. Four-State Nutr. Conf. MidWest Plan Service, Ames, IA.

Grohn, Y. T., P. J. Rajala-Schultz, H. G. Allore, M. A. DeLorenzo, J. A. Hertl, and D. T. Galligan. 2003. Optimizing replacement of dairy cows: Modeling the effects of diseases. Prev. Vet. Med. 61:27-43.

Hawkins, D. M., and D. H. Olwell. 1998. Cumulative Sum Charts and Charting for Quality Improvement. Springer-Verlag, New York, NY.

Henningsson, M., K. Ostergren, and P. Dejmek. 2005. The electrical conductivity of milk-the effect of dilution and temperature. Int. J. Food Prop. 8:15-22.

Hogeveen, H., and W. Ouweltjes. 2003. Sensors and management support in high-technology milking. J. Anim. Sci. 81(Suppl 3):110.

Huijps, K., T. J. Lam, and H. Hogeveen. 2008. Cost of mastitis: Facts and perception. J. Dairy Res. 75:113-120.

Huzzey, J. M., D. M. Veira, D. M. Weary, and M. A. von Keyserlingk. 2007. Prepartum behavior and dry matter intake identify dairy cows at risk for metritis. J. Dairy Sci. 90:3220-3233.

Kleen, J. L., G. A. Hooijer, J. Rehage, and J. P. T. M. Noordhuizen. 2003. Subacute ruminal acidosis (SARA): A review. J. Vet. Med. 50:406-419.

Loeffler, S. H., M. J. de Vries, and Y. H. Schukken. 1999. The effects of time of disease occurrence, milk yield, and body condition on fertility of dairy cows. J. Dairy Sci. 82:2589-2604.

Lucey, S., G. J. Rowlands, and A. M. Russell. 1986. Short-term associations between disease and milk yield of dairy cows. J. Dairy Res. 53:7-15

Macciotta, N. P., A. Cappio-Borlino, and G. Pulina. 2000. Time series autoregressive integrated moving average modeling of test-day milk yields of dairy ewes. J. Dairy Sci. 83:1094-1103.

Madsen, T. N., and A. R. Kristensen. 2005. A model for monitoring the condition of young pigs by their drinking behaviour. Comput. Electron. Agric. 48:138-154.

Milner, P., K. L. Page, and J. E. Hillerton. 1997. The effects of early antibiotic treatment following diagnosis of mastitis detected by a change in the electrical conductivity of milk. J. Dairy Sci. 80:859863.

Montgomery, D. C. 2005. Introduction to Statistical Quality Control. 5th ed. John Wiley \& Sons, Inc., New York, NY.
Mungube, E. O., B. A. Tenhagen, F. Regassa, M. N. Kyule, Y. Shiferaw, T. Kassa, and M. P. Baumann. 2005. Reduced milk production in udder quarters with subclinical mastitis and associated economic losses in crossbred dairy cows in Ethiopia. Trop. Anim. Health Prod. 37:503-512.

Nielen, M., H. Deluyker, Y. H. Schukken, and A. Brand. 1992. Electrical conductivity of milk: measurement, modifiers, and meta analysis of mastitis detection performance. J. Dairy Sci. 75:606-614.

Nielen, M., Y. H. Schukken, A. Brand, H. A. Deluyker, and K. Maatje. 1995. Detection of subclinical mastitis from on-line milking parlor data. J. Dairy Sci. 78:1039-1049.

Nielen, M., Y. H. Schukken, D. T. Scholl, H. J. Wilbrink, and A. Brand. 1989. Twinning in dairy cattle: A study of risk factors and effects. Theriogenology 32:845-862.

Nishimori, K., K. Okada, K. Ikuta, O. Aoki, T. Sakai, and J. Yasuda. 2006. The effects of one-time hoof trimming on blood biochemical composition, milk yield, and milk composition in dairy cows. J. Vet. Med. Sci. 68:267-270.

Nocek, J. E. 1997. Bovine acidosis: Implications on laminitis. J. Dairy Sci. 80:1005-1028.

Norberg, E., H. Hogeveen, I. R. Korsgaard, N. C. Friggens, K. H. Sloth, and P. Lovendahl. 2004. Electrical conductivity of milk: Ability to predict mastitis status. J. Dairy Sci. 87:1099-1107.

Nordlund, K., N. Cook, and G. Oetzel. 2006. Commingling dairy cows: Pen moves, stocking density, and health. Pages 36-42 in American Association Bovine Practitioners. AABP, St. Paul, MN.

Nordlund, K. V., and N. B. Cook. 2004. Using herd records to monitor transition cow survival, productivity, and health. Vet. Clin. North Am. 20:627-649.

Oltenacu, P. A., and I. Ekesbo. 1994. Epidemiological study of clinical mastitis in dairy cattle. Vet. Res. 25:208-212.

Prentice, J. H. 1972. The temperature coefficient of electrolytic conductivity of milk. J. Dairy Res. 39:275-278.

Quimby, W. F., B. F. Sowell, J. G. P. Bowman, M. E. Branine, M. E. Hubbert, and H. W. Sherwood. 2001. Application of feeding behaviour to predict morbidity of newly received calves in a commercial feedlot. Can. J. Anim. Sci. 81:315-320.

Rajala-Schultz, P. J., and Y. T. Grohn. 1999. Culling of dairy cows. Part I. Effects of diseases on culling in Finnish Ayrshire cows. Prev. Vet. Med. 41:195-208.

Rohrbach, B. W., A. L. Cannedy, K. Freeman, and B. D. Slenning, 1999. Risk factors for abomasal displacement in dairy cows. J Am. Vet. Med. Assoc. 214:1660-1663.

Seegers, H., C. Fourichon, and F. Beaudeau. 2003. Production effects related to mastitis and mastitis economics in dairy cattle herds. Vet. Res. 34:475-491.

Sheldrake, R. F., R. J. Hoare, and G. D. McGregor. 1983. Lactation stage, parity, and infection affecting somatic cells, electrical conductivity, and serum albumin in milk. J. Dairy Sci. 66:542547.

Stevenson, J. S., and E. P. Call. 1988. Reproductive disorders in the periparturient dairy cow. J. Dairy Sci. 71:2572-2583.

Valeeva, N. I., T. J. Lam, and H. Hogeveen. 2007. Motivation of dairy farmers to improve mastitis management. J. Dairy Sci. 90:44664477

Walsh, R. B., D. F. Kelton, T. F. Duffield, K. E. Leslie, J. S. Walton, and S. J. LeBlanc. 2007. Prevalence and risk factors for postpartum anovulatory condition in dairy cows. J. Dairy Sci. 90:315-324.

West, J. W. 2003. Effects of heat-stress on production in dairy cattle. J. Dairy Sci. 86:2131-2144.

Wilson, D. J., R. N. Gonzalez, J. Hertl, H. F. Schulte, G. J. Bennett, Y. H. Schukken, and Y. T. Grohn. 2004. Effect of clinical mastitis on the lactation curve: a mixed model estimation using daily milk weights. J. Dairy Sci. 87:2073-2084.

Woolford, M. W., J. H. Williamson, and H. V. Henderson. 1998 Changes in electrical conductivity and somatic cell count between milk fractions from quarters subclinically infected with particular mastitis pathogens. J. Dairy Res. 65:187-198. 